in vivo $35: 75-80(2021)$

doi:10.21873/invivo.12234

Review

\title{
Contemporary Molecular Classification of Urinary Bladder Cancer
}

\author{
DIMITRIOS GOUTAS ${ }^{1}$, ANDRIANOS TZORTZIS ${ }^{1}$, HARIKLEIA GAKIOPOULOU ${ }^{1}$, \\ DIMITRIOS VLACHODIMITROPOULOS ${ }^{2}$, IOANNA GIANNOPOULOU ${ }^{1}$ and ANDREAS C. LAZARIS ${ }^{1}$ \\ ${ }^{1}$ First Department of Pathology, School of Medicine, The National and Kapodistrian University of Athens - \\ Laikon General Hospital of Athens, Athens, Greece; \\ ${ }^{2}$ Laboratory of Forensic Medicine and Toxicology,
} The National and Kapodistrian University of Athens, Athens, Greece

\begin{abstract}
The significant heterogeneity in the clinical outcome among patients with bladder cancer has highlighted the existence of different biological subtypes of muscle-invasive and non-muscle-invasive bladder cancer. Transcriptional profiling studies revealed that primary bladder cancers can be grouped into 'intrinsic' basal and luminal molecular subtypes. Luminal tumors have a papillary configuration and express markers of urothelial differentiation (uroplakins, cytokeratin 20) fibroblast growth factor 3 (FGFR3), E-cadherin and early cell-cycle genes. On the contrary, basal tumors express markers of the basal layer of the urothelium (cluster of differentiation 44, cytokeratin 5/6 and cytokeratin 14); some show squamous differentiation. Patients with basal tumors respond better to immune checkpoint inhibitors and have a worse prognosis than those with luminal tumors, who respond better to FGFR3 and human epidermal growth factor receptor 2. Patients with squamous differentiation tumors show better response to agents targeting epidermal growth factor receptor. The aim of this review was to highlight the chronological order of research performed in the field of the molecular classification of bladder cancer, with particular emphasis on prototypical research projects and recent advances. If prospective studies confirm the association of bladder cancer molecular subtypes with different responses and prognoses to targeted therapies, molecular subtyping will be incorporated into bladder cancer management.
\end{abstract}

This article is freely accessible online.

Correspondence to: Dimitrios Goutas, Mikras Asias 75A, Goudi, Athens 11527, Greece. E-mail: goutas.dimitris@hotmail.com

Key Words: Bladder cancer, urology, pathology, molecular subtypes, molecular pathology, review.
All human cancers display a significant molecular heterogeneity, each constituting a distinct entity, with unique gene mutations, copy-number aberrations, DNA methylation and RNA expression patterns. However, mRNA expressionprofiling studies, performed on a larger scale, revealed that a significant number of human cancers can be grouped into molecular subtypes. In fact, all of the studies incorporated into The Cancer Genome Atlas (TCGA) showed that molecular subtypes can be found in most types of human cancer, each with different clinical and prognostic outcomes, as well as distinct responses to targeted therapies and non-targeted chemotherapy.

In general, bladder cancer can be divided into muscle-invasive (MIBC) and non-muscle-invasive (NMIBC), each with its own prognosis. MIBCs typically follow a rapid progression route and metastasize to lymph nodes, bones, lungs, liver and peritoneum, in that order of frequency (1). They tend to be aggressive with a usually fatal outcome. On the other hand, NMIBCs are less aggressive but do, however, recur, therefore requiring lifelong surveillance and surgical intervention. Furthermore, NMIBCs and MIBCs also display different histopathological characteristics. The former, mostly associated with papillary features, while the latter usually constituting flat lesions with often concomitant carcinoma in situ. Histological variants of invasive urothelial carcinoma exist, as per the World Health Organization 2016 classification of tumors (2), with some exhibiting a more aggressive behavior, such as micropapillary variant, sarcomatoid, clear-cell, small-cell/neuroendocrine and squamous differentiation (Figure 1).

\section{Molecular Subtypes}

In a study performed by Lindgren et al., gene-expression analysis and whole-genome array-comparative genomic hybridization was conducted on 144 carcinomas, identifying 

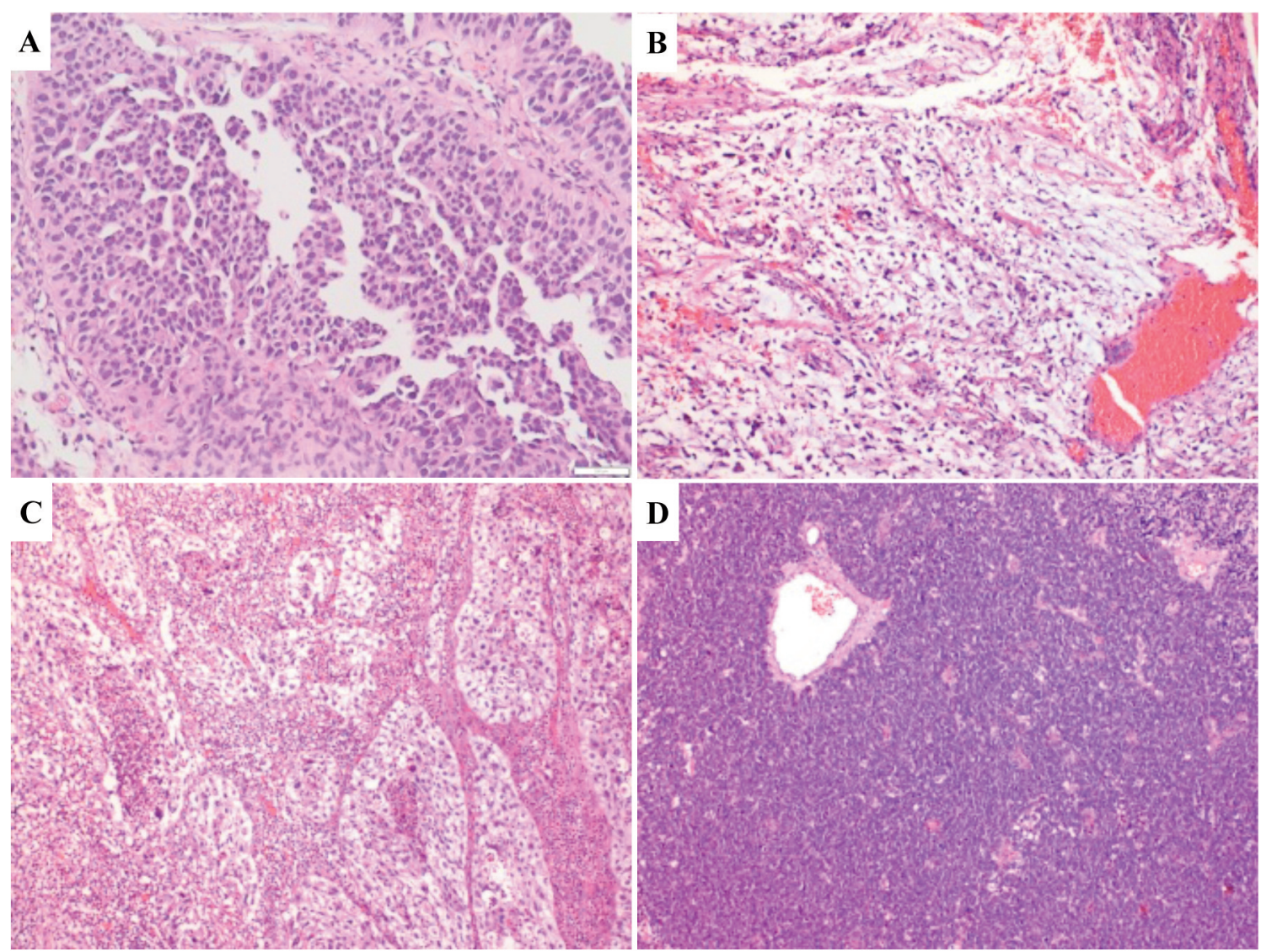

Figure 1. Aggressive histological variants of bladder cancer as revealed by hematoxylin and eosin staining. A: Micropapillary configuration ( $\times 200)$ B: Sarcomatoid differentiation $(\times 100)$. C: Clear-cell variant $(\times 40)$. D: Small-cell/neuroendocrine differentiation $(\times 100)$.

two intrinsic molecular subtypes, MS1 and MS2 (3), largely representing NMIBC and MIBC, respectively. The MS2/MIBC subtype revealed significant genomic instability, independent of TP53 inactivation, and higher frequency of TP53/Mouse double minute 2 homolog alterations, E2F transcription factor 3 (E2F3) amplifications and retinoblastoma 1 (RB1) losses than in the MS1/NMIBC class of tumors (3). On the other hand, fibroblast growth factor 3 (FGFR3) activating mutations were prevalent in the MS2/NMIBC subgroup, as well as phosphatidylinositol-4,5-bisphosphate 3-kinase catalytic subunit alpha (PIK3CA) activating mutations, which are connected to the downstream activation of the protein kinase B, also known as AKT pathway (3).

The Lund group of Sjodahl et al. then used gene-expression profiles from 308 tumors to further subdivide the MS1 and MS2 tumor classes (4). This process resulted in seven tumor clusters which were then incorporated into five major molecular subtypes, based on their biological characterization and the mutation distribution of PIK3CA, FGFR3 and TP53 genes. These five major molecular subtypes of urothelial cancer were designated urobasal A (MS1a and MS1b), genomically unstable (MS2a subdivided into MS2a1 and MS2a2), urobasal B (MS2b2.1), squamous-cell carcinoma-like [SCC-like (MS2b2.2)] and a highly infiltrated by non-tumor cells subtype (MS2b1). Among these, the urobasal B and SCC-like subtypes shared the worse prognosis, urobasal A had a good prognosis, while the genomically unstable tumors had an intermediate prognosis (4). Urobasal A tumors were found to be predominantly low-grade papillary, NMIBC with FGFR3 mutations and infrequent TP53 mutations. Urobasal B tumors were mostly of stage T1 or higher, displaying TP53 mutations and expressing markers of basal urothelium. They also showed homozygous cyclin-dependent kinase inhibitor 2A $(C D K N 2 A)$ deletions and an active FGFR3 pathway signature. Genomically unstable tumors were equally distributed between MIBC and high-grade NMIBC, suggesting that this subtype can rapidly progress, and characterized by genomic instability, high proliferation rates and frequent TP53 mutations. The SCC-like subtype expressed squamous differentiation markers and had frequent TP53 
Table I. Key points regarding consensus molecular classification of muscle-invasive bladder cancer.

\begin{tabular}{|c|c|c|c|c|c|}
\hline Molecular subtype & Differentiation & Mutation, $\%$ & Histology & Clinical features* & $\begin{array}{c}\text { Median survival, } \\
\text { years }\end{array}$ \\
\hline Luminal papillary (LumP) & Luminal & $\begin{array}{c}\text { KDM6A, 38\% } \\
F G F R 3,40 \% \\
C D K N 2 A, 33 \%\end{array}$ & Papillary morphology & pT2 and higher & 4 \\
\hline Luminal non-specified (LumNS) & Luminal & $E L F 3,35 \%$ & Micropapillary variant & Elderly patients & 1.8 \\
\hline Luminal unstable (LumU) & Luminal & $\begin{array}{c}\text { TP53, } 76 \% \\
E R C C 2,26 \% \\
A P O B E C^{+}\end{array}$ & & & 2.9 \\
\hline Stroma-rich & Intermediate & & & & 3.8 \\
\hline Basal/squamous (Ba/Sq) & Basal & $\begin{array}{c}T P 53,61 \% \\
R B 1,25 \%\end{array}$ & $\begin{array}{c}\text { Squamous } \\
\text { differentiation }\end{array}$ & $\begin{array}{l}\text { Women mostly } \\
\text { and pT3/pT4 }\end{array}$ & 1.2 \\
\hline Neuroendocrine-like (NE-like) & Neuroendocrine & $\begin{array}{l}T P 53,94 \% \\
R B 1,39 \%\end{array}$ & $\begin{array}{l}\text { Neuroendocrine } \\
\text { differentiation }\end{array}$ & & 1 \\
\hline
\end{tabular}

APOBEC: Apolipoprotein B mRNA editing enzyme, catalytic polypeptide-like; CDKN2A: cyclin-dependent kinase inhibitor 2A; ELF3: E74-like ETS transcription factor 3; ERCC2: excision repair cross-complementing rodent repair deficiency, complementation group 2; FGFR3: fibroblast growth factor 3; KDM6A: lysine-specific demethylase 6A; RB1: retinoblastoma protein; TP53: tumor protein p53. *According to (14).

mutations. Finally, the 'infiltrated' subtype was characterized by the presence of stromal and immune cells; therefore, this group of tumors was not regarded as an intrinsic subtype of urothelial carcinoma, with immunohistochemical evaluation revealing the expression of markers characteristic for the other subtypes (5). Furthermore, Sjodahl et al. demonstrated that the above molecular subtypes exist independent of pathological stratification. More specifically, some of the gene signatures showed coordinated expression, independently of the pathological stage and grade, conferring the molecular subtypes as intrinsic tumor features. Hence, molecular phenotyping will have a significant influence on behavior and treatment response of the tumor compared to pathological stratification (4). In 2015, the same group from Lund University used an independent dataset of 234 MIBCs from TCGA where they reproduced their original five subtypes and observed the appearance of a new subcategory of tumors with neuroendocrine differentiation as well as a novel 'infiltrated mesenchymal' subtype (5). Following this, Sjodahl et al. performed a global mRNA expression analysis (6) for phenotypic profiling of tumors which been employed to identify the molecular subtypes for nearly all major tumor types. They further analyzed 307 cystectomy specimens of advanced bladder cancer by immunohistochemistry, using antibodies for 28 proteins and by gene-expression analysis and defined five tumor cell phenotypes of MIBC: Urothelial-like, genomically unstable, basal/SCC-like, mesenchymal-like, and small-cell/neuroendocrine-like. However, they came to the conclusion that in global mRNA analyses, tumors with different phenotypes may co-cluster and tumors with identical phenotypes occasionally cluster apart, therefore creating disarray in molecular subtyping between global mRNA profiling and immunohistochemical profiling (6). Further studies were performed by a number of teams (7-9), including the University of North Carolina, the MD Anderson Cancer Center and TCGA (10-12), but they involved only MIBCs. The three groups identified the mutual expression of differentiation-associated biomarkers, previously linked to the intrinsic basal and luminal subtypes of breast cancer, and noted the fact that all MIBCs could be divided into two broad categories of basal and luminal type (10-12). All of the latter subtypes recognized by the groups revealed significant concordance among them $(11,13)$.

\section{Consensus Molecular Classification}

In 2019, an effort to achieve an international consensus on MIBC was made using 1,750 MIBCs from 16 published datasets and two additional cohorts (14) in order to compare six molecular classification schemes. Kamoun et al.defined with six molecular subtypes (Table I), labeled as luminal papillary (LumP), luminal nonspecified (LumNS), luminal unstable (LumU), stroma-rich, basal/squamous (Ba/Sq) and neuroendocrine-like (NE-like). They further analyzed seven bladder cancer genes most commonly mutated [CDKN2A, $F G F R 3$, proliferator-activated receptor gamma (PPARG), human epidermal growth factor receptor 2 (HER2; ERBB2), $T P 53, E 2 F 3$ and $R B 1$ ], and generated comprehensive profiles of their genomic alterations for each of the above subtypes. They observed that:

LumP subtype showed predominately FGFR3 mutations in up to $40 \%$ of cases, lysine-specific demethylase $6 \mathrm{~A}$ (KDM6A) mutations in $38 \%$ and homozygous deletions of CDKN2A in $33 \%$ of cases (14). 
The LumNS class of tumors demonstrated alterations mainly in PPARG (76\% of tumors) and in ELF3 $(35 \%)$ which is activated by PPARG and represents an early regulator of urothelial differentiation $(14,15)$.

On the other hand, LumU tumors showed the highest proportion of copy-number alterations, somatic mutations and apolipoprotein B mRNA editing enzyme, catalytic polypeptide-like (APOBEC)-induced mutations than any other class. More specifically, they demonstrated frequent TP53 (76\%) and ERCC2 (22\%) mutations, PPARG alterations $(89 \%)$ and amplifications at the $6 \mathrm{p} 22.3$ region consisting of E2F3 and SRY-related HMG-box 4 (SOX4) (76\%). Finally, HER2 (39\%) was overexpressed in this class of tumors, without, however, showing any type of association with the other tumor classes (14).

The stroma-rich tumors displayed overexpression of smooth muscle, myofibroblast, fibroblast and endothelial gene signatures and intermediate urothelial differentiation (14).

The $\mathrm{Ba} / \mathrm{Sq}$ tumors revealed an increased load of mutations in TP53 (61\%) and RBI (25\%) genes and were linked to genomic deletions of 3p14.2 in $49 \%$ of cases (14).

Finally, NE-like tumors demonstrated TP53 mutations occurring concurrently with $R B 1$ alterations (94\%), either mutations or deletions (14).

\section{Histological Variants}

Kamoun et al. (14) attempted to associate urothelial carcinoma histological variants with each of the above molecular classes. They concluded that LumP tumors exhibited a predominantly papillary configuration in 59\% of cases; however, this morphology was also observed in other luminal classes, LumU and LumNS, but to a lesser extent. LumNS tumors, for example, revealed a micropapillary configuration in $36 \%$ of cases and were significantly associated with carcinoma in situ in $80 \%$ of tumors. The neuroendocrine variant of urothelial carcinoma was mostly observed in the NE-like class of tumors, with $72 \%$ of the cases exhibiting neuroendocrine differentiation. In a similar way, $\mathrm{Ba} / \mathrm{Sq}$ tumors revealed features of squamous differentiation in a significant proportion of cases (79\%), confirming their molecular phenotype. The stroma-rich tumors exhibited a predominance of smooth-muscle cells, without being associated with a specific variant (13). To date, the only valid immunohistochemical method performed is the differentiation of basal tumors which express CK5/6 in cancerous cells from luminal tumors which are GATA3positive. In fact, Dadhania et al. (16) demonstrated that CK5/6 and GATA3 were sufficient to differentiate basal from luminal tumors with over $90 \%$ accuracy. Therefore, since the taxonomy has greatly evolved, further association and development of an appropriate immunohistochemical panel that is able to predict each molecular class might help integrate molecular subtyping of bladder cancer in routine pathology and indicate appropriate therapy and prognosis.

\section{Clinical Outcomes According to Consensus Molecular Subtypes}

The consensus group of scientists further attempted to associate molecular classes with clinical implications, prognosis and therapeutic possibilities, using age, gender and stage of the tumor for comparitive purposes. More specifically, $\mathrm{Ba} / \mathrm{Sq}$ tumors were mostly observed in advanced disease stages, with female predominance and a significant poor prognosis. They demonstrated increased expression levels of EGFR and its ligand, defining it, therefore, as a possible target therapy. They also revealed a possible immunotherapeutic potential, as these tumors expressed genes of the antigen processing and presenting machinery, as well as immune checkpoint markers. Patients with LumP were almost exclusively younger than 60 years of age and had the best prognostic outcome, along with patients with stroma-rich type of tumors. Furthermore, LumP and LumU tumors were usually of lower stage (T2), in contrast to the other types of tumors and LumNS tumors were mostly observed in patients over 80 years, with a median survival of 1.8 years. On the other hand, patients with LumU tumors had a slightly poorer prognosis and patients with NE-like exhibited the worst prognosis out of all molecular classes (14). Moreover, combining the mRNA signatures with evidence from responses to anti-programmed cell death 1 (PD1)/programmed cell death ligand (PD-L1) therapy revealed a relationship with increased interferon- $\gamma$ level, $\mathrm{CD}^{+} \mathrm{T}$-cells and reduced activity of the transforming growth factor-beta pathway. Nevertheless, none of the molecular classes were associated with either a desirable, or not, response to immune checkpoint inhibitors. Finally, the authors attempted to associate the outcomes of each molecular class after neoadjuvant chemotherapy or anti-PDL1 therapy. They concluded that patients with $\mathrm{Ba} / \mathrm{Sq}$ and LumNS tumors benefited from neoadjuvant chemotherapy and those with LumNS, LumU and NE-like from anti-PDL1 targeted therapy (17).

\section{Conclusion}

Further analysis of the new consensus molecular classification of bladder cancer, may provide a solution to intertumor heterogeneity (18) and disease-specific treatment focused on each subtype, delivering therefore the most appropriate regimen (19). FGFR3 overexpression or translocations and mutations in the tyrosine kinase domain of FGFR3 has been observed in the majority of patients with MIBC and has, thus, increased the interest of scientists in the development of FGFR3 inhibitor-targeted therapies that have 
already been associated with a clinical benefit in patients (2022). Other studies have shown benefits from the use of antivascular epidermal growth factor receptor 2 inhibitor ramucirumab, targeting the tumor vasculature in patients with platinum-refractory advanced or metastatic urothelial carcinoma (23). Furthermore, already widely used for many types of solid tumor, anti-PD1/PD-L1 immune checkpoint inhibition has also been integrated into the therapy of advanced or metastatic bladder cancer. Moreover, the need for developing an immunohistochemical panel that accurately predicts the molecular subtypes of the current consensus classification scheme needs to be highlighted so that such a panel can be incorporated into the everyday practice of pathologists and provide a more cost-effective approach.

\section{Conflicts of Interest}

None.

\section{Authors' Contributions}

All Authors contributed equally to the final version of the article.

\section{References}

1 Shinagare AB, Ramaiya NH, Jagannathan JP, Fennessy FM, Taplin ME and Van den Abbeele AD: Metastatic pattern of bladder cancer: Correlation with the characteristics of the primary tumor. Am J Roentgenol 196(1): 117-122, 2011. PMID: 21178055. DOI: $10.2214 /$ AJR.10.5036

2 Humphrey PA, Moch H, Cubilla AL, Ulbright TM and Reuter VE: The 2016 WHO Classification of Tumours of the Urinary System and Male Genital Organs-Part B: Prostate and Bladder Tumours. Eur Urol 70(1):106-119, 2016. PMID: 26996659. DOI: $10.1016 /$ j.eururo 2016.02 .028

3 Lindgren D, Frigyesi A, Gudjonsson S, Sjödahl G, Hallden C, Chebil G, Veerla S, Ryden T, Månsson W, Liedberg F and Höglund M: Combined gene expression and genomic profiling define two intrinsic molecular subtypes of urothelial carcinoma and gene signatures for molecular grading and outcome. Cancer Res 70(9): 3463-3472, 2010. PMID: 20406976. DOI: 10.1158/0008-5472.CAN-09-4213

4 Sjödahl G, Lauss M, Lövgren K, Chebil G, Gudjonsson S, Veerla S, Patschan $\mathrm{O}$, Aine M, Fernö M, Ringnér M, Månsson W, Liedberg F, Lindgren D and Höglund M: A molecular taxonomy for urothelial carcinoma. Clin Cancer Res 18(12): 3377-3386, 2012. PMID: 22553347. DOI: 10.1158/10780432.CCR-12-0077-T

5 Aine M, Eriksson P, Liedberg F, Sjödahl G and Höglund M: Biological determinants of bladder cancer gene expression subtypes. Sci Rep 5: 10957, 2015. PMID: 26051783. DOI: 10.1038/srep10957

6 Sjödahl G, Eriksson P, Liedberg F and Höglund M: Molecular classification of urothelial carcinoma: Global mRNA classification versus tumour-cell phenotype classification. J Pathol 242(1): 113-125, 2017. PMID: 28195647. DOI: $10.1002 /$ path. 4886
7 Marzouka NA, Eriksson P, Rovira C, Liedberg F, Sjödahl G and Höglund M: A validation and extended description of the Lund taxonomy for urothelial carcinoma using the TCGA cohort. Sci Rep 8(1): 3737, 2018. PMID: 29487377. DOI: 10.1038/s41598018-22126-x

8 Mo Q, Nikolos F, Chen F, Tramel Z, Lee YC, Hayashi K, Xiao $J$, Shen $J$ and Chan KS: Prognostic power of a tumor differentiation gene signature for bladder urothelial carcinomas. J Natl Cancer Inst 110(5): 448-459, 2018. PMID: 29342309. DOI: $10.1093 /$ jnci/djx243

9 Damrauer JS, Hoadley KA, Chism DD, Fan C, Tiganelli CJ, Wobker SE, Yeh JJ, Milowsky MI, Iyer G, Parker JS and Kim WY: Intrinsic subtypes of high-grade bladder cancer reflect the hallmarks of breast cancer biology. Proc Natl Acad Sci USA 111(8): 31103115, 2014. PMID: 24520177. DOI: 10.1073/pnas.1318376111

10 Tan TZ, Rouanne M, Tan KT, Huang RY and Thiery JP: Molecular subtypes of urothelial bladder cancer: Results from a meta-cohort analysis of 2411 tumors. Eur Urol 75(3): 423-432, 2019. PMID: 30213523. DOI: 10.1016/j.eururo.2018.08.027.

11 Choi W, Porten S, Kim S, Willis D, Plimack ER, HoffmanCensits J, Roth B, Cheng T, Tran M, Lee IL, Melquist J, Bondaruk J, Majewski T, Zhang S, Pretzsch S, Baggerly K, Siefker-Radtke A, Czerniak B, Dinney CP and McConkey DJ: Identification of distinct basal and luminal subtypes of muscleinvasive bladder cancer with different sensitivities to frontline chemotherapy. Cancer Cell 25(2):152-165, 2014. PMID: 24525232. DOI: $10.1016 /$ j.ccr.2014.01.009

12 Cancer Genome Atlas Research Network: Comprehensive molecular characterization of urothelial bladder carcinoma. Nature 507(7492): 315-322, 2014. PMID: 24476821. DOI: $10.1038 /$ nature 1296

13 McConkey DJ and Choi W: Molecular subtypes of bladder cancer. Curr Oncol Rep 20(10): 77, 2018. PMID: 30128829. DOI: 10.1007/s11912-018-0727-5.

14 Kamoun A, de Reyniès A, Allory Y, Sjödahl G, Robertson AG, Seiler R, Hoadley KA, Groeneveld CS, Al-Ahmadie H, Choi W, Castro MAA, Fontugne J, Eriksson P, Mo Q, Kardos J, Zlotta A, Hartmann A, Dinney CP, Bellmunt J, Powles T, Malats N, Chan KS, Kim WY, McConkey DJ, Black PC, Dyrskjøt L, Höglund M, Lerner SP, Real FX, Radvanyi F; Bladder Cancer Molecular Taxonomy Group: A consensus molecular classification of muscle-invasive bladder cancer. Eur Urol 77(4): 420-433, 2020. PMID: 31563503. DOI: 10.1016/j.eururo.2019.09.006

15 Böck M, Hinley J, Schmitt C, Wahlicht T, Kramer S and Southgate J: Identification of ELF3 as an early transcriptional regulator of human urothelium. Dev Biol 386(2): 321-330, 2014. PMID: 24374157. DOI: 10.1016/j.ydbio.2013.12.028

16 Dadhania V, Zhang M, Zhang L, Bondaruk J, Majewski T, Siefker-Radtke A, Guo CC, Dinney C, Cogdell DE, Zhang S, Lee S, Lee JG, Weinstein JN, Baggerly K, McConkey D and Czerniak B: Meta-analysis of the luminal and basal subtypes of bladder cancer and the identification of signature immunohistochemical markers for clinical use. EBioMedicine 12: 105-117, 2016. PMID: 27612592. DOI: 10.1016/j.ebiom.2016.08.036

17 Kim J, Kwiatkowski D, McConkey DJ, Meeks JJ, Freeman SS, Bellmunt J, Getz G and Lerner SP: The Cancer Genome Atlas expression subtypes stratify response to checkpoint inhibition in advanced urothelial cancer and identify a subset of patients with high survival probability. Eur Urol 75(6): 961-964, 2019. PMID: 30851984. DOI: 10.1016/j.eururo.2019.02.017 
18 Warrick JI, Sjödahl G, Kaag M, Raman JD, Merrill S, Shuman L, Chen G, Walter V and DeGraff DJ: Intratumoral heterogeneity of bladder cancer by molecular subtypes and histologic variants. Eur Urol 75(1): 18-22, 2019. PMID: 30266310. DOI: $10.1016 / j$.eururo.2018.09.003

19 Griffin JL: Devil in the detail: Intratumour heterogeneity and personalised medicine for bladder cancer. Eur Urol 75(1): 2324, 2019. PMID: 30292329. DOI: 10.1016/j.eururo.2018.09.036

20 Schuler M, Nogova L, Heidenreich A, Tai D, Cassier P, Richly H, Cho BC, Sayehli CM, Navarro A, Bender S, Ocker M, Nogai $\mathrm{H}$, Wagner A, Ince S, Ellinghaus $\mathrm{P}$ and Joerger M: Anti-tumor activity of the pan-FGFR inhibitor rogaratinib in patients with advanced urothelial carcinomas selected based on tumor FGFR mRNA expression levels. Ann Oncol 28(suppl_5): mdx371.013, 2017. DOI: $10.1093 /$ annonc/mdx371.013

21 Pal SK, Rosenberg JE, Hoffman-Censits JH, Berger R, Quinn DI, Galsky MD, Wolf J, Dittrich C, Keam B, Delord JP, Schellens JHM, Gravis G, Medioni J, Maroto P, Sriuranpong V, Charoentum C, Burris HA, Grünwald V, Petrylak D, Vaishampayan U, Gez E, De Giorgi U, Lee JL, Voortman J, Gupta S, Sharma S, Mortazavi A, Vaughn DJ, Isaacs R, Parker K, Chen X, Yu K, Porter D, Graus Porta D and Bajorin DF: Efficacy of BGJ398, a fibroblast growth factor receptor 1-3 inhibitor, in patients with previously treated advanced urothelial carcinoma with FGFR3 alterations. Cancer Discov 8(7): 812-821, 2018. PMID: 29848605. DOI: 10.1158/2159-8290.CD-18-0229
22 Loriot Y, Necchi A, Park SH, Garcia-Donas J, Huddart R, Burgess E, Fleming M, Rezazadeh A, Mellado B, Varlamov S, Joshi M, Duran I, Tagawa ST, Zakharia Y, Zhong B, Stuyckens K, Santiago-Walker A, De Porre P, O'Hagan A, Avadhani A, Siefker-Radtke AO; BLC2001 Study Group: Erdafitinib in locally advanced or metastatic urothelial carcinoma. N Engl J Med 381(4): 338-348, 2019. PMID: 31340094. DOI: 10.1056/NEJMoa1817323

23 Petrylak DP, de Wit R, Chi KN, Drakaki A, Sternberg CN, Nishiyama H, Castellano D, Hussain S, Fléchon A, Bamias A, Yu EY, van der Heijden MS, Matsubara N, Alekseev B, Necchi A, Géczi L, Ou YC, Coskun HS, Su WP, Hegemann M, Percent IJ, Lee JL, Tucci M, Semenov A, Laestadius F, Peer A, Tortora G, Safina S, Del Muro XG, Rodriguez-Vida A, Cicin I, Harputluoglu H, Widau RC, Liepa AM, Walgren RA, Hamid O, Zimmermann AH, Bell-McGuinn KM, Powles T; RANGE study investigators: Ramucirumab plus docetaxel versus placebo plus docetaxel in patients with locally advanced or metastatic urothelial carcinoma after platinum-based therapy (RANGE): A randomised, doubleblind, phase 3 trial. Lancet 390(10109): 2266-2277, 2017. PMID: 28916371. DOI: 10.1016/S0140-6736(17)32365-6

Received October 6, 2020

Revised October 28, 2020

Accepted October 30, 2020 